\title{
USAGE OF DYNAMIC ANALYSIS TO DETERMINE FORCE INTERACTIONS BETWEEN COMPONENTS OF ROLLING BEARINGS
}

The aim of this paper is to detail the creation of a roller bearing model in the Adams program suite for subsequent dynamic analysis and to obtain information about different parts of the bearing during the simulation. The bearing model was made so as to closely resemble its reallife counterpart, which allows us to estimate load conditions, dynamic conditions of individual bearing parts and interactions between them.

\section{Introduction}

This article details the creation of a virtual bearing model allowing the analysis of individual bearing components under dynamic behavior. Two models of tapered roller bearings will be employed: one with steel cage and the other with plastic cage, both of which are pictured in Fig. 1 along with the assembled bearing model.

\section{Tapered roller bearing model}

Dynamic simulations of the tapered roller bearing were performed in the MSC.Adams system. A precise geometrical model of the bearing was necessary in order to perform the said simulations. The 3D model was created based on available drawing docu- mentation and incorporates various methods with regards to the overall model complexity. Model design was performed in Pro/Engineer Wildfire 5 (Fig. 1), which, when compared to the MSC.Adams environment, allows simpler model creation and subsequently easier bearing geometry modifications. The bearing model assembly was transformed from Pro/Engineer into Adams environment using the Parasolid file format and was further processed based on analysis requirements. The first step included material definition for individual bearing components. The bearing consists of inner and outer ring, cage and rollers. Table 1 lists values assigned to individual parts.

In the next step we defined the contacts between individual bearing components. Contact type "solid to solid" was chosen for the afore mentioned operation, defining two objects coming into contact. This was due to the geometrical complexity of the model
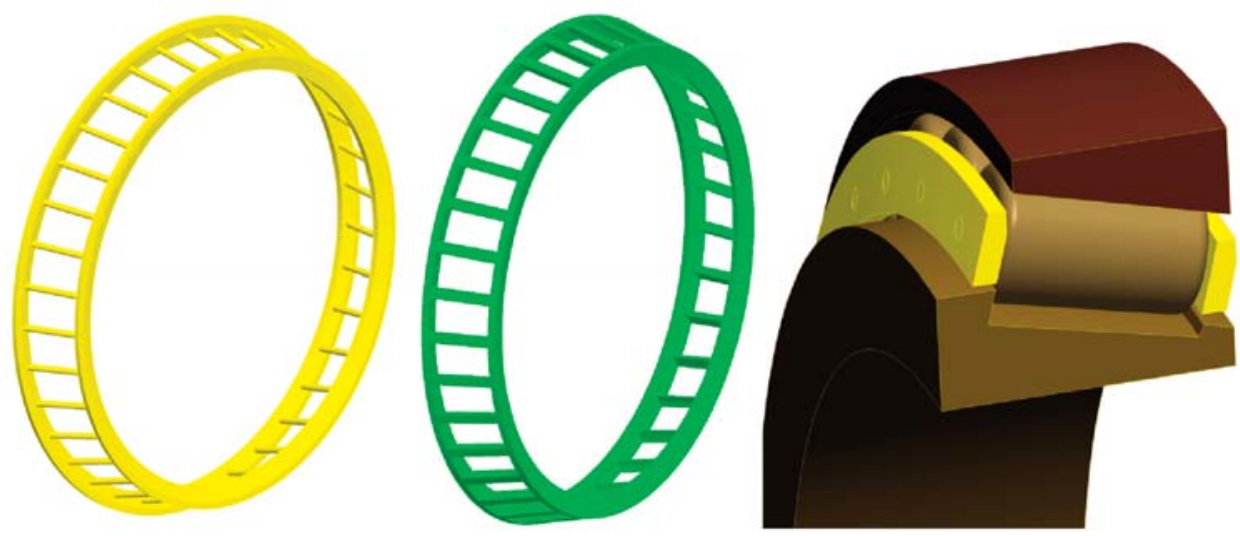

Fig. 1 Tapered roller bearing model in Pro/Engineer

\footnotetext{
* Robert Kohar, Slavomir Hrcek, Stefan Medvecky

Faculty of Mechanical Engineering, University of Zilina, Slovakia, E-mail: robert.kohar@fstroj.uniza.sk
} 
Material properties of individual bearing parts

\begin{tabular}{|c|c|c|c|}
\hline & $\begin{array}{c}\text { Density } \\
\left(\mathrm{kg}^{-3} \mathrm{~m}^{-3}\right)\end{array}$ & $\begin{array}{c}\text { Young modulus } \\
(\mathrm{MPa})\end{array}$ & $\begin{array}{c}\text { Poisson } \\
\text { constant (-) }\end{array}$ \\
\hline Inner ring & 7850 & 202000 & 0.29 \\
\hline Outer ring & 7850 & 202000 & 0.29 \\
\hline Roller & 7850 & 202000 & 0.29 \\
\hline Steel cage & 7850 & 202000 & 0.29 \\
\hline Plastic cage & 1100 & 3000 & 0.42 \\
\hline
\end{tabular}

and inability to determine all bearing parts that come into contact. This contact type requires the definition of the following parameters to define the normal force which is based on an impact using the "Impact" function [1]: Stiffness, Exponent, Max Damping and Penetration Distance. Contact pairs were formed between inner ring and rollers, outer ring and rollers and between ring and rollers. Parameter values for contact between cage and rollers were defined as per [1]. Parameter values for contacts of rollers with outer and inner ring were defined based on the Hertz theory of contact pressure for tapered roller bearing. Table 2 lists values of parameters for individual contacts. We also considered a friction model based on Coulomb friction force calculation. Values of static and dynamic friction coefficient were set according to [2] and values of transmission velocity according to [1] which are generalized values for the model with friction effects at the contact locations using Coulomb friction model in Adams.

Contact parameters used in the tapered roller bearing model Table2

\begin{tabular}{|c|c|c|c|c|}
\hline \multirow{3}{*}{ Parameter } & \multicolumn{4}{|c|}{ Contact pairs } \\
\hline & \multirow{2}{*}{$\begin{array}{c}\text { Roller } \\
\text { - outer } \\
\text { ring }\end{array}$} & \multirow{2}{*}{$\begin{array}{c}\text { Roller } \\
\text { - inner } \\
\text { ring }\end{array}$} & \multicolumn{2}{|c|}{ Roller - cage } \\
\hline & & & steel & Plastic \\
\hline Stiffness $\left(\mathrm{N} \cdot \mathrm{mm}^{-1}\right)$ & 9870000 & 9870000 & 100000 & 80000 \\
\hline Exponent (-) & 1.5 & 1.5 & 1.5 & 1.8 \\
\hline Max. Damping (N.s.mm ${ }^{-1}$ ) & 10000 & 10000 & \multicolumn{2}{|c|}{100} \\
\hline Penetration Distance $(\mathrm{mm})$ & 0.15 & 0.15 & \multicolumn{2}{|c|}{0.1} \\
\hline Static coefficient (-) & 0.12 & 0.12 & 0.12 & 0.1 \\
\hline Dynamic coefficient (-) & 0.1 & 0.1 & 0.1 & 0.06 \\
\hline $\begin{array}{l}\text { Stiction transition velocity } \\
\left(\mathrm{mm} \cdot \mathrm{s}^{-1}\right)\end{array}$ & 100 & 100 & \multicolumn{2}{|c|}{100} \\
\hline $\begin{array}{l}\text { Friction transition velocity } \\
\qquad\left(\mathrm{mm} \cdot \mathrm{s}^{-1}\right)\end{array}$ & 1000 & 1000 & \multicolumn{2}{|c|}{1000} \\
\hline
\end{tabular}

Next we defined the geometric and kinematic constraint conditions and load force. Axial load force of the outer ring was associated with "Fixed joint"constraint, which resulted in removal of all degrees of freedom. The inner ring was associated with "Cylindrical Joint" constraint condition, which allowed rotation and translation along the $\mathrm{x}$ axis. "Rotational Joint Motion" of type "Velocity" was assigned to the "Cylindrical Joint" constraint, allowing rotational movement. This movement was defined via the STEP function [1] and corresponds to bearing rotational speed $n=15.5 \mathrm{~min}^{-1}$. Loading force was defined via gravitation acceleration "Gravity" and "Axial Force" of magnitude $518000 \mathrm{~N}$ in $x$ axis direction, influencing the inner ring. Figure 2 left shows a model with axial load force with defined geometrical and kinematic constraint conditions.

Constraint conditions for dynamic analysis with radial load force were defined as following: "Revolute Joint" was assigned to the inner ring and allowed inner ring rotation around the $\mathrm{x}$ axis. "Translational Joint" was assigned to the outer ring, allowing movement in direction of the y axis. "Rotational Joint Motion" of type "Velocity" was assigned to the aforementioned constraint, allowing rotational movement. This movement was defined in a similar fashion as described above using the STEP function. Loadforce was defined via gravitation acceleration "Gravity" and "Radial Force" of magnitude $4500000 \mathrm{~N}$ was applied in $y$ axis direction, influencing the outer ring. Figure 2 right shows the model under radial load force with defined geometric and kinematic constraint conditions.

After defining all constraint conditions, boundary conditions and loadforce, we defined the analysis type and solved parameters as follows:

$$
\text { SIMULATE/DYNAMIC, END }=30, \text { STEPS }=3000
$$

Integrator GSTIFF, Formulation SI2, Corrector Modified, Error 1e-2, Executable External C++, Thread Count 8, Contacts Default Library, Faceting Tolerance 1e5.

\section{Dynamic simulation results - axial load force}

Dynamic simulation results with axial load force represent force interactions between individual bearing parts, movement of bearing cage center of gravity and angular velocity thereof. Figure 3 shows forces between roller and cage, roller and inner ring and angular velocity of this roller. Maximum force between steel cage and rollers was observed during interaction of the cage with roller n. 26 and is equal to $268 \mathrm{~N}$ (Fig. 3 up, green line). Also shown is the force between inner ring and roller n. 26 (red line), which varied between $54297 \mathrm{~N}$ and $59103 \mathrm{~N}$, a difference of $4.2 \%$ (minimal force) and $8.1 \%$ (maximal force) when compared to theoretical calculations. The blue line displays angular velocity of roller n. 26 and varies between $483^{\circ} / \mathrm{s}$ and $495^{\circ} \mathrm{s}$.

Maximum force between plastic cage and rollers was observed during interaction of the cage with roller $n .2$ and is equal to $251 \mathrm{~N}$ (Fig. 3 down, green line). Also shown is the force between inner ring and roller n. 2 (red line), which varied between $54467 \mathrm{~N}$ and $58636 \mathrm{~N}$ and was lower when compared to the steel cage, representing a difference of $3.9 \%$ (minimal force) and $7.1 \%$ (maximal force) when compared to theoretical calculations. The blue line displays angular velocity of roller n. 2 and varies between $483^{\circ} / \mathrm{s}$ and $495^{\circ} / \mathrm{s}$, similar to the velocity observed for the steel cage. 

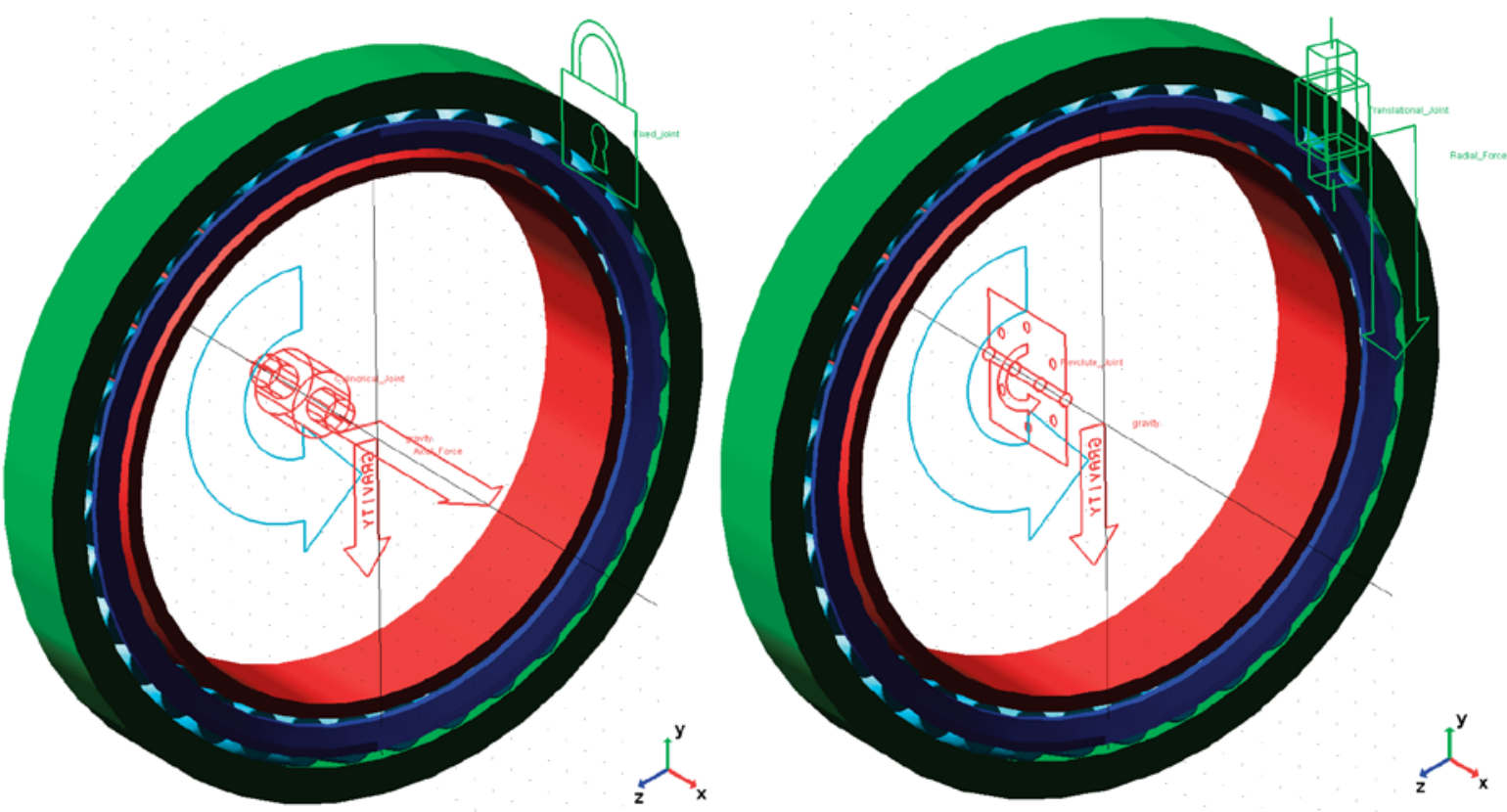

Fig. 2 Definition of geometric and kinematic constraint conditions - axial load force - left, radial load force - right

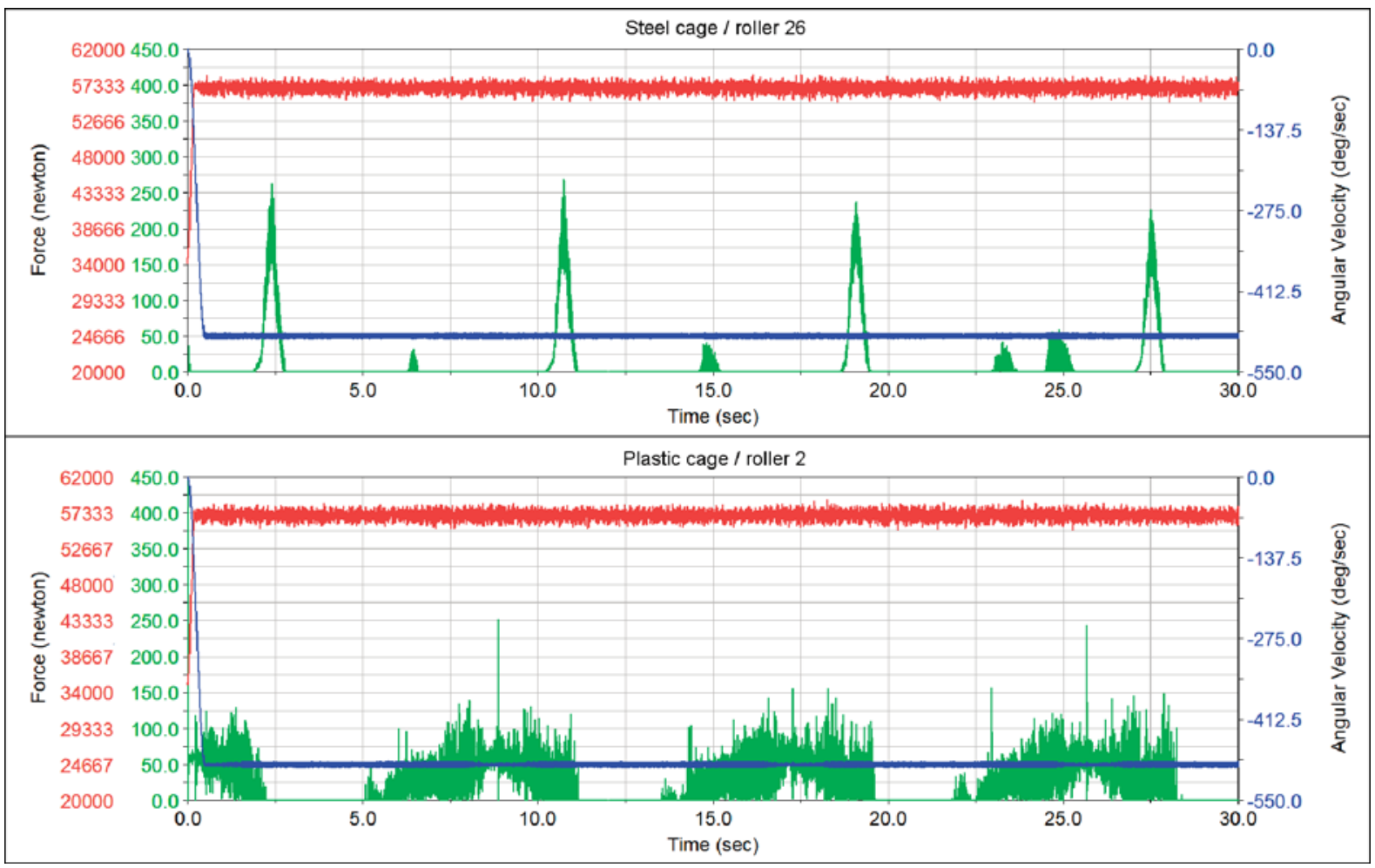

Fig. 3 Force interaction between inner ring and rollers (red lines), force interaction between cage and rollers (green lines) and angular velocity of rollers. 
Figure 4 left shows the movement of steel cage center of gravity in $x, y$ andz axes oriented as per Fig. 2. It is evident that minimum change of center of gravity is within the rotation axis ( $x$ axis, up to $0.007 \mathrm{~mm}$ ) and maximum change in the $y-z$ plane, wherein the deviation in the $y$ axis is equal to $0.419 \mathrm{~mm}$ and in $z$ axis up to $0.649 \mathrm{~mm}$.

Figure 4 right shows the movement of plastic cage center of gravity. It is evident that the center of gravity deviation increased within the rotation axis ( $x$ axis) to $0.605 \mathrm{~mm}$ when compared to the steel cage and also increased in the $y-z$ plane, wherein the deviation in the $y$ axis was equal to $0.599 \mathrm{~mm}$ and $0.919 \mathrm{~mm}$ for the $\mathrm{z}$ axis. Figure 4 down shows the center of gravity location in the $y-z$ plane.

\section{Dynamic simulation results - radial load force}

Similar to axial load force, we calculated force interactions between individual bearing parts, movement of bearing cage and angular velocity thereof when subjected to radial force. Figure 5 shows force between roller and cage, roller and inner ring and angular velocity of the roller. Also shown is the force between inner ring and roller n.13 (red line). Maximum force between steel cage and rollers was observed for roller n.13 and is equal to $706 \mathrm{~N}$ (green line). The analysis also showed that highest load rates are present at rollers 10 to 14 during start-up time (2-5 seconds) and are equal to $700 \mathrm{~N}$. During subsequent simulation time, the cage was in contact with rollers only when the rollers were off-loaded

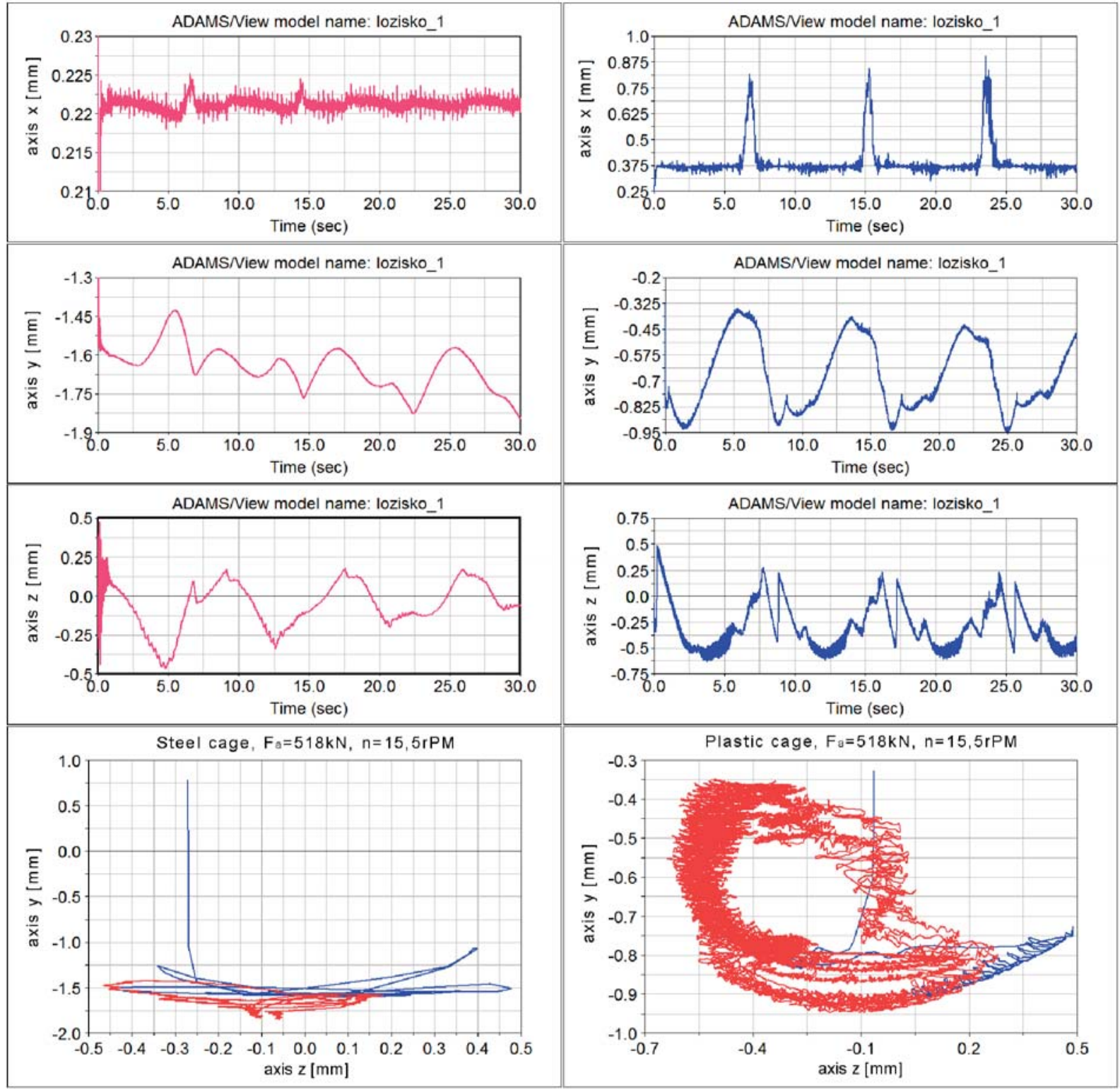

Fig. 4 Movement of center of gravity of steel and plastic cages in the $y$-z plane, axial load force 
and maximum force value was equal to $250 \mathrm{~N}$. Angular speed was constant $\left(489^{\circ} / \mathrm{s}\right)$ under applied roller load and lowered under roller load in the $20000 \mathrm{~N}$ to $70000 \mathrm{~N}$ range, achieving a minimum value of $445^{\circ} / \mathrm{s}$ (blue curve).

Figure 5 down shows force between inner ring and roller n.10 (red line) for bearing with plastic cage. Maximum force between plastic cage and rollers was observed for roller n.13 and is equal to $706 \mathrm{~N}$ (green line). Maximum force between the plastic cage and rollers was observed for roller n.10 and is equal to $670 \mathrm{~N}$ (green line). Similar to the steel cage, highest load rates were present at rollers 10 to 14 during start-up time ( $2-5$ seconds) and are equal to $700 \mathrm{~N}$. When compared to the steel cage, the rollers were in contact not only in the off-load phase (force equal to $100 \mathrm{~N}$ ) but also during the load phase, with the force equal to $400 \mathrm{~N}$. Angular speed was constant $\left(489^{\circ} / \mathrm{s}\right)$ under applied roller load and, similar to the steel cage, lowered under roller load in the $20000 \mathrm{~N}$ to $70000 \mathrm{~N}$ range, achieving a minimum value of $167^{\circ} \%$ s (blue curve) and $320 \%$ under load.

Figure 6 left shows the movement of steel cage center of gravity in $x, y$ and $z$ axes oriented as per Fig. 2. The change of center of gravity within the rotation axis ( $x$ axis) is equal to $0.026 \mathrm{~mm}$ and maximum change is in the $y-z$ plane, wherein the deviation in the $y$ axis is up to $0.433 \mathrm{~mm}$ and in the $z$ axis up to $0.711 \mathrm{~mm}$. Figure 6 right shows the movement of plastic cage center of gravity. It is evident that the center of gravity deviation in the rotation axis $(x$ axis) is similar that of the steel cage $(0.605 \mathrm{~mm})$, however decreased in the $y-z$ plane, wherein the deviation in the $y$ axis was $0.345 \mathrm{~mm}$ and $0.575 \mathrm{~mm}$ for the $z$ axis. Figure 6 down shows the center of gravity location of the cages in the $y-z$ plane.

\section{Conclusion}

The aim of this article was to detail the creation of a tapered roller bearing model in the Adams software suite to be used for further dynamic analysis and to obtain information about individual parts during the simulation process. The bearing model was made so as to closely resemble its real-life counterpart and thus allowed us to extract information about load transfer conditions, kinematic ratios and mutual component interactions. This approach can help identify problematic parts during the development phase and allows modification of the bearing design before the actual manufacturing process, thus maximizing the overall service life-time of the bearing.

This work was supported by the Slovak Research and Development Agency under the contract No. APVV-0087-10 - Intelligent Diagnostic Systems of Gearboxes and their Components.

This work was supported by the Slovak Research and Development Agency under the contract No. APVV-0419-11 - Adaptation of modern computer-simulation methods to the development of rolling bearings and their verification in real conditions.

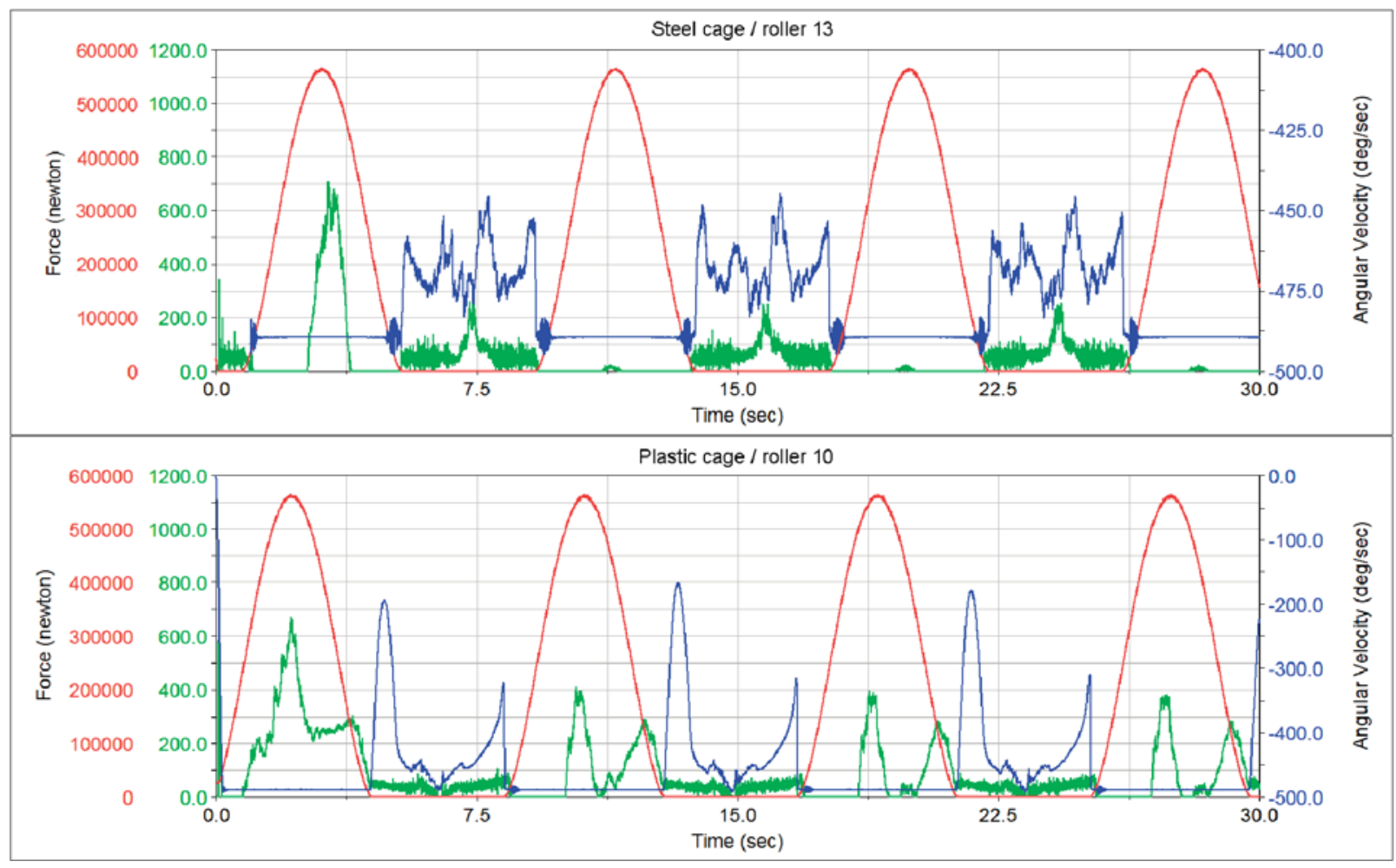

Fig. 5 Force interaction between inner ring and rollers (red lines), force interaction between cage and rollers (green lines), angular velocity of rollers (blue line) 


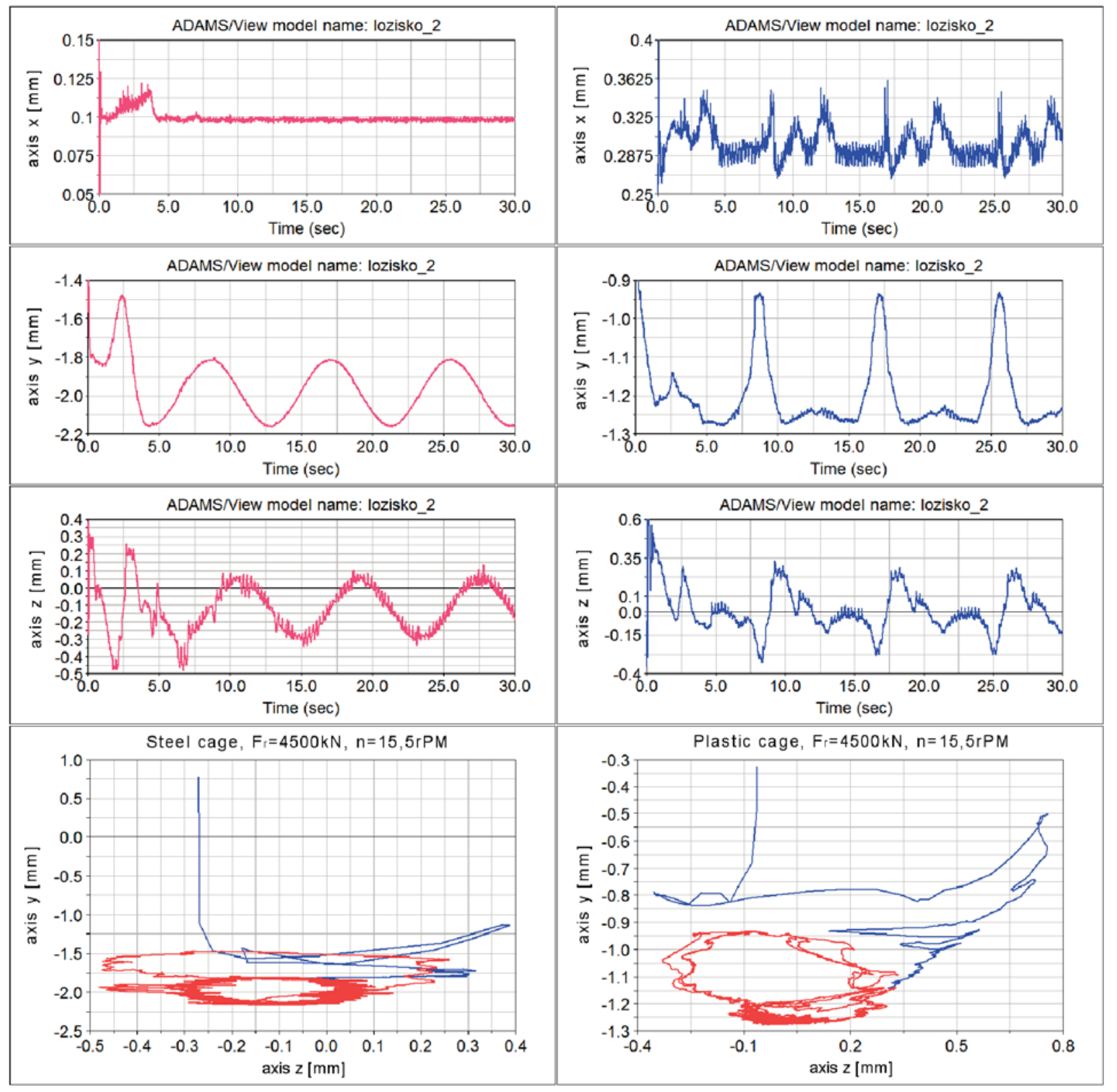

Fig. 6 Movement of center of gravity of cages in the y-z plane under axial load

\section{References:}

[1] MD Adams 2011 Online Help.

[2] HARRIS, T. A., KOTZALAS, M. N.: Essential Concepts of Bearing Technology. 5. edition. 2007. 